\title{
THE
}

\section{Parents Do Matter: A Longitudinal Two-Part Mixed Model of Early College Alcohol Participation and Intensity}

\author{
Mark D. Wood \\ University of Rhode Island, mark_wood@uri.edu \\ Theodore A. Walls \\ University of Rhode Island, walls@uri.edu \\ Anne M. Fairlie \\ University of Rhode Island
}

Follow this and additional works at: https://digitalcommons.uri.edu/psy_facpubs

Terms of Use

All rights reserved under copyright.

\section{Citation/Publisher Attribution}

Walls, T. A., Fairlie, A. M. \& Wood, M. D. (2009). Parents Do Matter: A Longitudinal Two Part Mixed Model of Early College Alcohol Participation and Intensity, Journal of Studies on Alcohol and Drugs, 70(6), 908-918. doi: 10.15288/jsad.2009.70.908

Available at: http://dx.doi.org/10.15288/jsad.2009.70.908

This Article is brought to you for free and open access by the Psychology at DigitalCommons@URI. It has been accepted for inclusion in Psychology Faculty Publications by an authorized administrator of DigitalCommons@URI. For more information, please contact digitalcommons-group@uri.edu. 


\title{
Parents Do Matter: A Longitudinal Two-Part Mixed Model of Early College Alcohol Participation and Intensity*
}

\author{
THEODORE A. WALLS, PH.D. ${ }^{\dagger}$ ANNE M. FAIRLIE, M.A., AND MARK D. WOOD, PH.D. ${ }^{\dagger}$ \\ Department of Psychology, University of Rhode Island, 10 Chafee Road, Suite 8, Kingston, Rhode Island 02881
}

\begin{abstract}
Objective: We hypothesized that etiologically relevant parental, peer, and demographic variables would predict both the transition into alcohol use and consequences and the increase in intensity of these outcomes from prematriculation to the sophomore year of college. Method: College students $(N=388)$ at a midsized northeastern public university were assessed during the summer before matriculation and during the spring semesters of their freshman and sophomore years. A recently developed mixed model for analyzing longitudinal response patterns with predominating zeros was employed to examine categorical transitions (binary portion) and growth (intensity portion). Results: As expected, there were strong effects of time reflected in both the binary and intensity portions of the models across the three outcomes (weekly alcohol use, heavy episodic drinking, and alcohol-related problems).
\end{abstract}

Parental permissiveness of drinking and student intention to affiliate with fraternity/sorority organizations predicted the transition to use and consequence status for all three outcomes and for increases in alcohol use and consequences. Peer disapproval of drinking strongly predicted all alcohol use and consequence outcomes. Parental disapproval of heavy drinking, parental monitoring, and male gender were variably influential across the outcomes at low to moderate levels. Conclusions: Our findings indicate the importance of the parental context (e.g., parental permissiveness of drinking) as well as peer influences (e.g., intended fraternity/sorority involvement) in drinking behavior among college students. These findings underscore the need to examine both onset and growth of drinking outcomes. Intervention and prevention implications are explored. (J. Stud. Alcohol Drugs 70: 908-918, 2009)
$\mathrm{C}^{\mathrm{s}}$ IOLLEGE STUDENT ALCOHOL USE continues to be an area of particular concern (Hingson et al., 2005; O'Malley and Johnston, 2002; Wechsler et al., 2000). The college transition has been identified as a particularly risky period for increases in alcohol use and consequences (Baer et al., 1995; Read et al., 2005; White et al., 2006). For example, from the summer before matriculation to the first semester in college, significant increases have been observed in heavy drinking among college students (Sher and Rutledge, 2007). Precollege drinking norms, prior substance use, and precollege party motivation predicted heavy drinking during the first semester of college.

Given the scope and chronicity of college student alcohol use, it is important to further study possible causes of drinking over this important developmental stage. The development of alcohol use and misuse across adolescence is a complex and dynamic biopsychosocial process (Brown et al., 2008; Windle et al., 2008). Parental and peer influences

Received: August 8, 2008. Revision: June 9, 2009.

*This research was supported by funding from the Alcoholic Beverage Medical Research Foundation to Mark D. Wood and by support under a Mentored Research Scholar Award from the American Cancer Society to Theodore A. Walls.

${ }^{\dagger}$ Correspondence may be sent to Theodore A. Walls and Mark D. Wood at the above address or via email at: walls@uri.edu and mark_wood@uri. edu. are important factors affecting the ontogeny of alcohol use both directly and indirectly through their interaction with other risk and protective factors (Hawkins et al., 1992; Sher, 1991). For example, Masten and Shaffer (2006) illustrate ways in which parents influence children's behavior under the risk and resilience perspective. Among these factors, most germane to the current research is a framework in which parents' beliefs and practices serve to moderate the impact of risk factors, decreasing, for example, the robust influence of peers on the initiation and escalation of alcohol use and misuse (Marshall and Chassin, 2000; Wood et al., 2004). This framework is consistent with a number of social and developmental theoretical perspectives (Bronfenbrenner, 1979; Dishion and Stormshak, 2007; Dodge et al., 2006).

This study is concerned with the roles of peers and parents in relation to college students' drinking behavior. Peer factors have been widely acknowledged as playing a central role in the development and maintenance of alcohol use among college students (Borsari and Carey, 2001; White et al., 2006). Previous research has supported the etiologic relevance of active and passive social influences (Read et al., 2005; Wood et al., 2001) and descriptive and injunctive norms (Borsari and Carey, 2003). Of particular interest, peer disapproval of alcohol use has been identified as an important predictor of alcohol use among college students (Borsari and Carey, 2006; Lo and Globetti, 1993). Among students who were nondrinkers in high school, friends' dis- 
couragement of drinking has been found to predict drinking status in college (Lo and Globetti, 1993). Also, Reifman and Watson (2003) found that, among students who did not report heavy episodic drinking in high school, students who reported greater levels of friends' approval of drinking were also more likely to report heavy episodic drinking during the first semester in college. Conversely, among students who reported engaging in heavy episodic drinking in high school, friends' approval of drinking was not related to heavy episodic drinking during the first semester of college. This suggests that friends' approval of drinking may have a greater influence on those who do not yet engage in heavy episodic drinking. Thus, preliminary evidence indicates that peer factors are differentially related to the initiation and maintenance of alcohol use during the college years.

There is also an extensive body of literature documenting the important role that parents have on the development of substance use during early adolescence (Barnes et al., 1994; Guilamo-Ramos et al., 2005; van der Vorst et al., 2005). Promotive or protective parental influences have been associated with delayed onset and with slower growth in adolescent alcohol use. Although originally crafted for early childhood, Baumrind's (1967, 1971; see also Buri, 1991) influential model of parenting may provide a useful vantage point from which to frame consideration of these influences. Baumrind (1991) theorized that optimal childhood outcomes occur when parents are both highly demanding and highly responsive, a style characterized as "authoritative." Specifically, demands include clear expectations for age-appropriate mature behavior and obedience, whereas responsiveness includes empathic understanding toward the child as well as responsiveness to the child's needs. The constructs under study in this article-parental monitoring, parental permissiveness of drinking, and parental disapproval of drinking — are most consistent with Baumrind's dimension of "demandingness." Other constructs involving proactive warmth and support from parents perhaps better correspond to the dimension of parental responsiveness.

Previous research has minimized the potential influence that parents may have in the context of college student drinking (Ham and Hope, 2003). However, a growing body of largely cross-sectional research suggests that parents do in fact continue to influence their children's alcohol use during the college years (Patock-Peckham and Morgan-Lopez, 2006; Turrisi et al., 2000; Wood et al., 2004). In a college-age sample, low parental monitoring prospectively predicted heavy episodic drinking but not alcohol use frequency (White et al., 2006). Abar and Turrisi (2008) found that parental monitoring assessed at prematriculation predicted first semester alcohol use, with indirect effects on second semester drinking mediated by close friends' drinking. Parental disapproval of drinking has also been negatively associated with college student alcohol use and consequences both cross-sectionally and longitudinally (Boyle and Boekeloo, 2006; Jessor et al.,
2006). However, there has been mixed support for parents' discouragement or disapproval of drinking in predicting drinking status among nondrinking college students (Lo and Globetti, 1993; Weitzman et al., 2003).

There is a strong need for additional longitudinal studies that examine predictors of the transition into drinking and the intensity of alcohol involvement across a range of alcohol-related outcomes (e.g., alcohol-related consequences). Accordingly, in this study, we examined three primary outcomes: weekly alcohol use, heavy episodic drinking, and alcoholrelated consequences. By incorporating the examination of both the likelihood of transitioning to use and consequences and changes in the intensity of use and consequences over the first 2 years of college, the work presented here extends previous cross-sectional (Wood et al., 2004) and longitudinal (Capone et al., 2007; Read et al., 2005) analyses that have been reported on these data. We investigated whether parent and peer factors predicted both the likelihood of transitioning to use and consequences and the intensity. We hypothesized that intended fraternity/sorority involvement and parental permissiveness of drinking would be positively associated with the likelihood of transitioning and the intensity over time, whereas parental monitoring, parental disapproval of drinking, and peer disapproval of drinking would be negatively associated with the likelihood of transitioning and the intensity.

\section{Method}

\section{Participants}

Incoming college students $(N=388)$ were recruited for a longitudinal study at a midsized public university in the northeastern United States. From an eligible sample of the 578 baseline (prematriculation) respondents, 416 students (all 191 men and 225 randomly selected women) were targeted for a longitudinal study. Of these, 388 students $(93 \%$ of those targeted) participated at Wave 2 in the spring of their freshman year, and 355 (85.3\% of those targeted) participated at Wave 3 in the spring of their sophomore year. At baseline, participants continuing in the longitudinal study had an average (SD) age of 18.1 years $(0.22)$. The majority of participants $(87.4 \%, n=339)$ were white, followed by Asian (4.4\%, $n=17)$, Hispanic $(2.3 \%, n=9)$, black $(2.1 \%$, $n=8)$, Native American $(0.2 \%, n=1)$, and other ethnicity or multiracial $(3.3 \%)$. One participant did not report race and ethnicity data. In comparison with the university's population of incoming freshmen for the same academic year, whites were somewhat overrepresented in the sample $(87 \%$ vs $77.5 \%)$, whereas Hispanics $(2.3 \%$ vs $3.6 \%)$ and blacks $(2.1 \%$ vs $3.6 \%)$ were slightly underrepresented. University data indicate that $10.4 \%$ of incoming freshmen did not provide race or ethnicity data. Women composed $56 \%$ of both the sample and the population of incoming freshmen. 


\section{Recruitment procedure}

Participants were recruited from a sample of 2,117 incoming freshmen (96\% of the incoming class) attending summer orientation. During this orientation, students viewed an on-line announcement inviting first-time freshmen to participate in a study of "college student health behaviors and attitudes." We received 970 e-mail inquiries about the project. Prospective participants were mailed a cover letter, consent form, and a baseline questionnaire packet. Follow-up recruitment efforts included two rounds of telephone calls, postcard reminders, and resending of mail surveys, resulting in completed questionnaires from 589 respondents. Of these, 11 were eliminated because they were outside the study's 18- to 19-years-old age requirement, which was established because we wished to examine peer and parental influences among first-time entering freshmen. From this pool of 578 respondents, all 191 men and 225 randomly selected women were targeted for the longitudinal arm of the study to ensure roughly equal representation of men and women. All participants provided informed consent. Questionnaires were completed by mail at baseline and were typically completed on site at follow-up. At Waves 2 and 3, 21 and 48 participants, respectively, completed questionnaires by mail rather than on site. Incentives for participation were $\$ 8.00$ for completing the baseline questionnaire, $\$ 20.00$ at Wave 2, and $\$ 25.00$ at Wave 3. At both Waves 2 and 3, participants had a chance to win one of five $\$ 50.00$ gift certificates.

\section{Measures}

As noted, students completed a baseline assessment in the summer before matriculation and two follow-up assessments in the spring of the freshman and sophomore years. From this larger battery, the following measures were used in the current study.

Demographics. Participants were assessed on gender (0 = female, 1 = male) and age. Intended fraternity or sorority involvement was assessed at baseline in the summer before matriculation using a 5-point scale ranging from $0=$ "definitely will be joining" to $4=$ "definitely will not be joining." This item was reversed and recoded to reflect three categories of intended fraternity/sorority involvement: 104 students (26.8\%) reported that they definitely will not be joining a fraternity or sorority; 137 students $(35.3 \%)$ reported that they probably will not be joining; and 147 students $(37.9 \%)$ reported that they may join or definitely will be joining.

\section{Predictors}

Peer disapproval of drinking. Four items were administered at baseline to measure how the students perceived their close friends' disapproval of heavy drinking and impaired driving (Wood et al., 2004). For example, students were asked, "How would your close friends feel if you had five or more drinks once or twice each weekend?" Responses ranged from $0=$ "approve" to 2 = "disapprove." The four items were summed to create a total score (Cronbach's $\alpha=$ $.73)$.

Parent disapproval of drinking. Four items, which paralleled the peer disapproval items, were administered at baseline to measure students' perceptions of parent disapproval of heavy drinking and impaired driving (Cronbach's $\alpha=.81$; Wood et al., 2004).

Parental monitoring. At baseline, students were queried about their perceptions of parental monitoring using six items (Wood et al., 2004). Three items assessed how much the parents try to know where the student goes at night, what the student does with free time, and where the student goes after school. Three parallel items assessed students' perceptions of how much the parents really knew. Responses ranged from $0=$ "don't try/know" to $2=$ "try/know a lot." The six items were summed to create a total score (Cronbach's $\alpha=$ $.85)$.

Parental permissiveness of drinking. Two items were averaged to assess students' perceptions of parental permissiveness of drinking (Wood et al., 2004). At baseline, the students retrospectively reported the number of drinks their mother and father considered to be an upper limit to consume on any given occasion during the senior year of high school.

\section{Outcome measures}

Weekly alcohol use. Seven items queried the students about the number of drinks they had, on average, for each day of the week (Baer et al., 2001). At the baseline assessment participants were queried retrospectively about their average drinking during the senior year of high school. At the two follow-up assessments, participants were queried about their average drinking during the school year, which corresponded with the freshman and sophomore years of college. At each of the three assessments, the seven items were summed to create an index of the typical number of drinks students consumed per week.

Heavy episodic drinking. At baseline, heavy episodic drinking was assessed retrospectively using a single item that measured the number of times students had consumed five or more drinks in a row in a typical 2-week period during the senior year of high school (Wood et al., 2004). Parallel items were used at the follow-ups, which referred to a typical 2-week period during the freshman and sophomore years of college. Participants responded on a 6-point scale: none, once, twice, 3-5 times, 6-9 times, and 10 or more times. Responses were recoded as $0,1,2,4,8$, and 11 times.

Alcohol-related consequences. Alcohol-related consequences were assessed with a modified (24-item) version of the Young Adult Alcohol Problems Screening Test (Hurlbut 
and Sher, 1992). This measure assesses the frequency of several common negative consequences of alcohol use, including drinking and driving, feeling physically sick, and unwanted sexual behaviors. Nine items with higher base rates (e.g., having a hangover) were assessed on a 10-point scale ranging from $0=$ "no, never" to $9=$ "40 or more times." Fifteen items with lower base rates were assessed using a 5point scale ranging from $0=$ "no, never" to $4=$ " 3 or more times." Participants were asked about negative consequences during the past year at baseline and during the past 6 months at Waves 2 and 3 to ensure nonoverlapping response intervals at the shorter interval (Wave 2). Responses were recoded to reflect the number of times the students had experienced the consequence. The higher base rate items were recoded as $0-40$ and the low base rate items were recoded as 0 to 3 . Items were summed to create a single indicator of alcoholrelated consequences at each assessment. Alpha coefficients for this measure were $.90, .91$, and .91 at Waves 1, 2, and 3, respectively.

\section{Analytical approach}

In college-age population samples, alcohol use data reflect substantial amounts of consumption, heavy episodic drinking, and alcohol-related problems (O'Malley and Johnston, 2002; Wechsler et al., 2000). However, a sizable number of students enter college never having consumed alcohol. This results in positively skewed distributions on the drinking response variables, frequently with predominating zeroes. The statistical literature has considered cases with nonnormal response distributions for several years (Johnson and Kotz, 1969; Olsen and Schafer, 2001). Prevailing strategies have included transformation-based approaches and the use of alternative underlying distributions in regression frameworks (Land et al., 1996). Recent scholarship has led to several versions of specialized "two-part" regression-based models to enable researchers to properly analyze these data in the case of counts (Duan et al., 1983; Lambert, 1992) and continuous responses (Olsen and Schafer, 2001; Tooze et al., 2002). Our main analytic goal was to characterize the sources of variation that are associated with either (1) beginning to drink for the first time, or (2) the intensity with which drinking occurs after inception. Because the dependent variables were interval-level indicators with a high positive skew and high zero count, we chose a recently emerging model for analysis of data with this distributional form for the response. In this article, we utilized an approach developed by Tooze and colleagues (2002) involving a two-part, or mixed distribution, model based on two distributions. In this particular model, estimates from the two parts of the model are allowed to covary. The model formulation by Tooze and colleagues draws from earlier work by Duan et al. (1983), Grunwald and Jones (2000), Lachenbruch (1992), Lambert (1992), and Manning et al. (1981). Additional applications of two-part models include Brown et al. (2005) in the area of substanceuse intervention for youth, Mabry et al. (2007) in tobacco use research, and Witkiewitz and Masyn (2008) in the area of relapse after treatment for alcohol abuse or dependence. For this study, the approach enables consideration of both the transition into participation in drinking behavior (e.g., from 0 drinks at Time 1) and the intensity of the behavior once drinking is engaged in (reflecting the trend of drinking level among those who drink). Similarly, this approach enables conjoint consideration of the transition to alcohol-related consequences as well as the intensity of consequences among those who have experienced consequences.

Because this model has seen limited application in the alcohol literature, we outline the key aspects briefly. We refer to drinking as the response variable generically for model illustration; however, our response variables are the three outcomes detailed earlier. Two distributions are used in the mixed distribution model developed by Tooze et al. (2002): the binomial distribution, for the transition into drinking status, and either a normal or lognormal distribution for the drinking intensity when participants report drinking at least once. These distributions and related estimation algorithms were drawn from a macro that integrates parameters from the PROC GENMOD and the PROC NLMIXED procedures in SAS, Version 9.1.3 (SAS Institute Inc., Cary, NC), and also accounts for possible covariation of the two parts. The macro is available from Tooze and colleagues upon request. The overall model deployed by this macro can be written in SAS as a single combined likelihood for the two parts and fitted with a quasi-Newton optimization of a likelihood approximated by adaptive Gaussian quadrature. For practical application, the model is more easily expressed by the two equations that are estimated initially by independent GENMOD and NLMIXED runs, one for each part of the model, and a statement clarifying the common parameter $\rho$, which reflects possible covariation between the two parts of the model. The key equations for the model are shown below. First, let $R_{i j}$ represent the occurrence of drinking behavior. A random variable $Y_{i j}$, represents the amount of a quantity with observed value $y_{i j}$ for a unit of observation $i$ at time $j$ :

$$
R_{i j}=\left\{\begin{array}{l}
0, \text { if } Y_{i j}=0 \\
1, \text { il } Y_{i j}>0
\end{array}\right.
$$

Given this, the conditional probability of occurrence is defined as:

$$
\operatorname{Pr}\left(R_{i j}=r_{i j} \mid \theta_{1}\right)=\left\{\begin{array}{c}
1-p_{i j}\left(\theta_{1}\right), \text { if } r_{i j}=0 \\
p_{i j}\left(\theta_{1}\right), \text { if } r_{i j}=1
\end{array}\right.
$$

where $\theta_{1}=\left[\beta_{1}^{\prime}, u_{1 i}\right]^{\prime}$ is comprised of a vector of fixed occurrence effects $\beta_{1}$ and random unit occurrence effect $u_{1 i}$. The resulting general specification of the logistic model for occurrence is based on 


$$
\operatorname{logil}\left(p_{i j}\left(\theta_{1}\right)\right)=X_{1 i j}^{\prime} \beta_{1}+u_{i j}
$$

A second random variable is defined as the intensity variable conditional on the occurrence variable

$$
S_{i j} \equiv\left[Y_{i j} \mid R_{i j}=1\right. \text {. }
$$

and the general form for specification of the lognormal model becomes:

$$
\log \left(S_{i j} \mid \theta_{22}\right) \sim N\left(X_{2 i j}^{\prime} \beta_{22}+u_{2 i}, \sigma_{e}^{2}\right) .
$$

The $\mathrm{X}$ vectors in each equation reflect the inclusion of covariates that explain the occurrence or intensity effects.

More generally, the binomial distribution is used as the underlying distribution for the binary portion in which the responses reflect whether a behavior has occurred (e.g., alcohol use vs no alcohol use), therefore, modeling the probability of a nonzero value. Either the normal or lognormal distribution can be used for the intensity portion to describe the probability distribution of the nonzero values. For instance, the outcome in the intensity portion may be the typical number of drinks consumed per week, given that alcohol use has occurred.
For our analyses, we deployed the following model for each of the three alcohol-related outcomes, employing the lognormal distribution for the intensity part of the model:

Alcohol outcome $=$ Gender $\beta_{1}+$ Baseline Fraternity/Sorority Status $\beta_{2}+$ Parental Monitoring $\beta_{3}+$ Parental Permissiveness of Drinking $\beta_{4}+$ Parental Disapproval $\beta_{5}+$ Peer Disapproval $\beta_{6}+$ Time $\beta_{7}$

where the $X_{1 i j}^{\prime}$ and $X_{2 i j}^{\prime}$ observed vectors were the same (as listed above) for both the binary and intensity parts of the model. Time was coded as $0,0.5$, and 1.5 to reflect the unequally spaced intervals between assessments.

\section{Results}

The results of the binary (use vs nonuse) and intensity (frequency of the nonzero values) portions of the correlated model are depicted in Figure 1, Panels 1 and 2, respectively, and are described below. Parameter estimates, standard errors, and probability values are shown in Tables 1-3 for weekly alcohol use, heavy episodic drinking, and alcoholrelated consequences, respectively. The significant positive

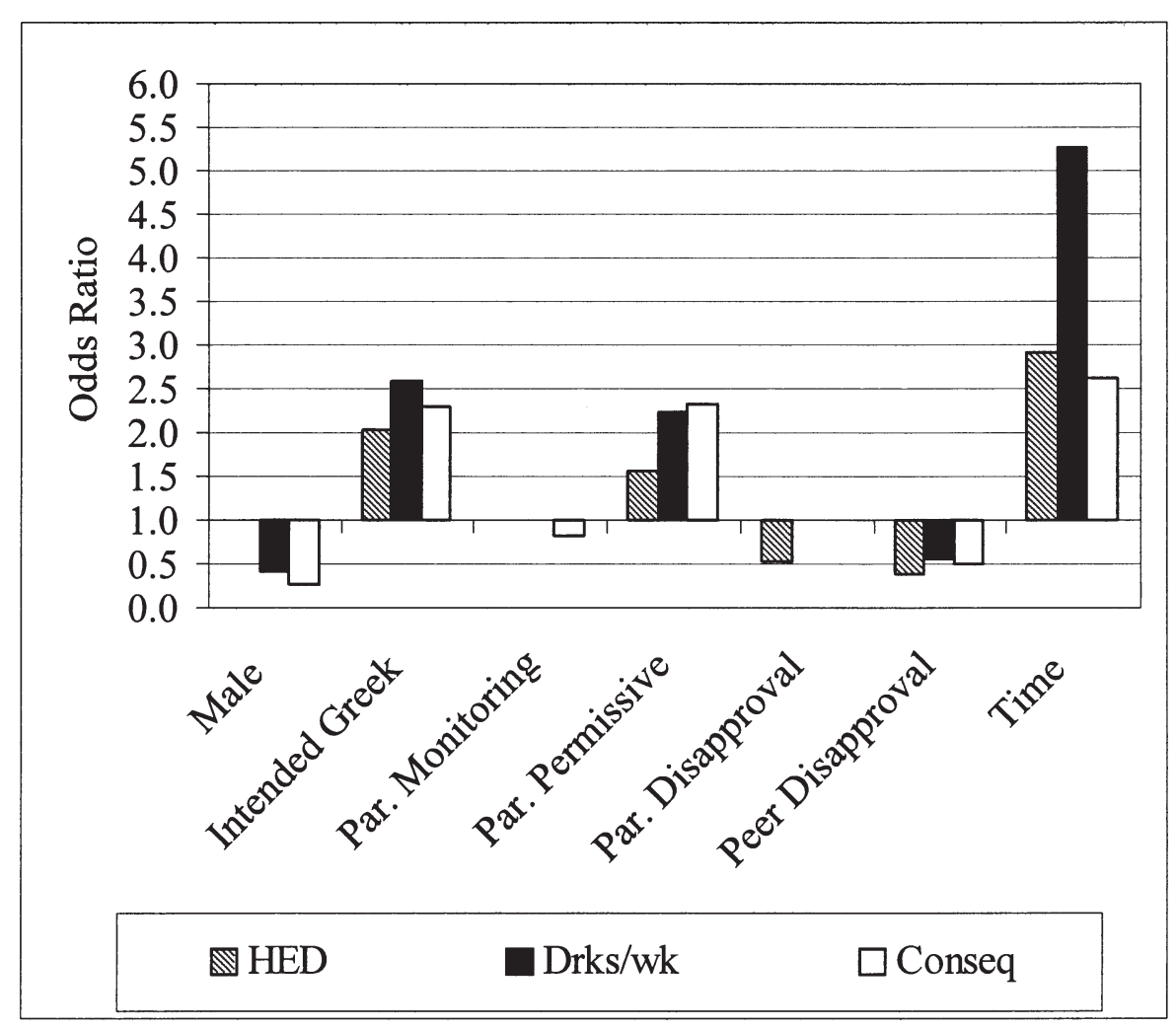

FIGURE 1, PANEL 1. Results of the binary portion of the models. Outcomes were heavy episodic drinking (HED), weekly alcohol use, and alcohol-related consequences. Only significant predictors are shown. For the predictor "male," the odds ratio is interpreted as the amount that the odds of transitioning on the outcome decreases for men compared with women (e.g., half the odds of transitioning). For the continuous predictors, the odds ratio is interpreted as the amount that the odds of transitioning on the outcome will change for each one-unit increase in the predictor. If the odds ratio is positive, then the odds of transitioning increases; if the odds ratio is negative, then the odds of transitioning decreases. Greek = fraternity $/$ sorority involvement; Par. $=$ parental; HED $=$ heavy episodic drinking; drks/wk = drinks per week; conseq = consequences. All $p$ 's $<.05$. 


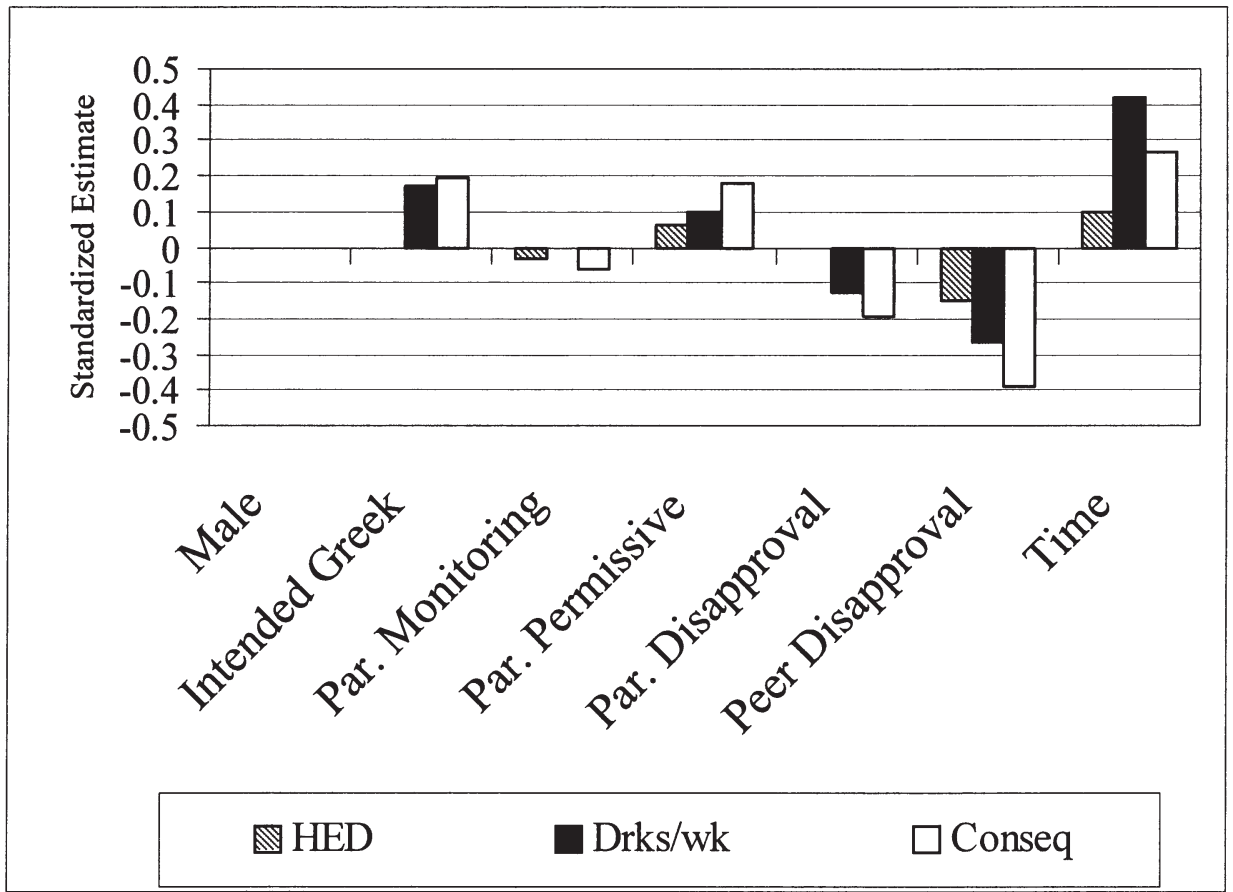

Figure 1, PANel 2. Results of the intensity portion of the models. Outcomes were heavy episodic drinking (HED), weekly alcohol use, and alcohol-related consequences. Only significant predictors are shown. Greek $=$ fraternity/sorority involvement; Par. $=$ parental; HED $=$ heavy episodic drinking; drks $/$ wk $=$ drinks per week; conseq $=$ consequences. All $p$ 's $<.05$.

covariance displayed in Tables 1-3 indicates that individuals who were more likely to begin weekly drinking, to engage in heavy episodic drinking, or to experience consequences were also more likely to increase in the intensity of the behavior over the first 2 years of college.

TABLE 1. Results of the correlated mixed distribution model for weekly alcohol use

\begin{tabular}{|c|c|c|c|}
\hline Variable & Estimate & $\begin{array}{l}\text { Standard } \\
\text { error }\end{array}$ & $p$ \\
\hline \multicolumn{4}{|l|}{ Binary portion } \\
\hline Intercept & 16.26 & 6.37 & .01 \\
\hline Gender & -0.88 & 0.38 & .02 \\
\hline Intended fraternity/sorority & 0.95 & 0.24 & $<.0001$ \\
\hline Parental monitoring & -0.13 & 0.07 & .06 \\
\hline Parental permissiveness for drinking & 0.80 & 0.14 & $<.0001$ \\
\hline Parent disapproval for drinking & -1.49 & 0.78 & .06 \\
\hline Peer disapproval for drinking & -0.59 & 0.16 & $<.001$ \\
\hline Time & 1.66 & 0.21 & $<.0001$ \\
\hline Variance & 6.64 & 1.49 & $<.0001$ \\
\hline \multicolumn{4}{|l|}{ Intensity portion } \\
\hline Intercept & 4.24 & 0.52 & $<.0001$ \\
\hline Gender & 0.13 & 0.09 & .13 \\
\hline Intended fraternity/sorority & 0.17 & 0.05 & $<.01$ \\
\hline Parental monitoring & -0.03 & 0.01 & .05 \\
\hline Parental permissiveness for drinking & 0.10 & 0.03 & $<.001$ \\
\hline Parent disapproval for drinking & -0.13 & 0.06 & .02 \\
\hline Peer disapproval for drinking & -0.27 & 0.03 & $<.0001$ \\
\hline Time & 0.42 & 0.04 & $<.0001$ \\
\hline Residual & 0.40 & 0.03 & $<.0001$ \\
\hline Variance & 0.38 & 0.05 & $<.0001$ \\
\hline Covariance & 1.23 & 0.20 & $<.0001$ \\
\hline
\end{tabular}

\section{Results of the binary portion}

The binary portion of each of Tables 1-3 shows logistic regression parameters reflecting the probability of transitioning to alcohol use (Tables 1 and 2) or beginning to experi-

TABLE 2. Results of the correlated mixed distribution model for heavy episodic drinking

\begin{tabular}{lrcc}
\hline Variable & \multicolumn{3}{c}{ Standard } \\
& Estimate & error & $p$ \\
\hline Binary portion & & & \\
$\quad$ Intercept & 9.64 & 2.68 & $<.001$ \\
Gender & 0.16 & 0.30 & .59 \\
Intended fraternity/sorority & 0.71 & 0.19 & $<.001$ \\
Parental monitoring & -0.10 & 0.05 & .06 \\
Parental permissiveness for drinking & 0.45 & 0.10 & $<.0001$ \\
Parent disapproval for drinking & -0.63 & 0.31 & .04 \\
Peer disapproval for drinking & -0.94 & 0.14 & $<.0001$ \\
Time & 1.07 & 0.16 & $<.0001$ \\
Variance & 4.12 & 0.86 & $<.0001$ \\
Intensity portion & & & \\
Intercept & 2.04 & 0.42 & $<.0001$ \\
Gender & 0.14 & 0.08 & .07 \\
Intended fraternity/sorority & 0.04 & 0.05 & .41 \\
Parental monitoring & -0.03 & 0.01 & .04 \\
Parental permissiveness for drinking & 0.06 & 0.02 & .02 \\
Parent disapproval for drinking & -0.06 & 0.04 & .14 \\
Peer disapproval for drinking & -0.15 & 0.03 & $<.0001$ \\
Time & 0.10 & 0.05 & .04 \\
Residual & 0.38 & 0.03 & $<.0001$ \\
Variance & 0.15 & 0.04 & $<.001$ \\
Covariance & 0.73 & 0.15 & $<.0001$ \\
\hline
\end{tabular}


ence alcohol-related consequences (Table 3) over subsequent time points. Logistic regression parameters are usually interpreted as odds ratios. Using Table 1 as an example, by taking the exponent of 0.95 for intended fraternity/sorority involvement, the odds ratio obtained is 2.59 . Given that intended fraternity/sorority involvement is measured on a 3-point scale, for each 1-unit increase in this predictor the odds of transitioning to weekly drinking increases by 2.59 . For ease of interpretation, we have graphed these odds ratios in Figure 1, Panel 1, for all of the significant predictors.

Men were significantly less likely than women to transition to weekly drinker status and to begin experiencing alcohol-related consequences. Students who intended to affiliate with the fraternity/sorority system during college were significantly more likely to transition to weekly alcohol use, heavy episodic drinking, and consequences, corresponding to an increase of about twice the odds of transitioning for each 1-unit increase in intended fraternity/sorority involvement. Students who perceived higher parental monitoring during the summer before college were significantly less likely, by about three-quarters of the odds for each 1-unit increase in parental monitoring, to transition to experiencing alcohol-related consequences. Students who perceived that their parents were more permissive about drinking during the students' senior year of high school were significantly more likely to transition to weekly alcohol use, heavy episodic drinking, and consequences during college, again about twice the odds for each 1-unit increase in parental permissiveness of drinking.

Students who perceived greater parent disapproval of heavy drinking during the summer before college were significantly less likely to transition to heavy episodic drinker

TABLE 3. Results of the correlated mixed distribution model for alcoholrelated consequences

\begin{tabular}{lrcc}
\hline Variable & Standard & \\
& Estimate & error & $p$ \\
\hline Binary portion & & & \\
$\quad$ Intercept & 15.31 & 5.95 & .01 \\
Gender & -1.36 & 0.39 & $<.001$ \\
Intended fraternity/sorority & 0.83 & 0.23 & $<.001$ \\
Parental monitoring & -0.19 & 0.07 & $<.01$ \\
Parental permissiveness for drinking & 0.84 & 0.14 & $<.0001$ \\
Parent disapproval for drinking & -1.07 & 0.73 & .14 \\
Peer disapproval for drinking & -0.71 & 0.17 & $<.0001$ \\
Time & 0.96 & 0.18 & $<.0001$ \\
Variance & 6.32 & 1.42 & $<.0001$ \\
Intensity portion & & & \\
Intercept & 6.31 & 0.77 & $<.0001$ \\
Gender & -0.14 & 0.13 & .28 \\
Intended fraternity/sorority & 0.19 & 0.08 & .01 \\
Parental monitoring & -0.06 & 0.02 & $<.01$ \\
Parental permissiveness for drinking & 0.18 & 0.04 & $<.0001$ \\
Parent disapproval for drinking & -0.19 & 0.08 & .02 \\
Peer disapproval for drinking & -0.39 & 0.05 & $<.0001$ \\
Time & 0.27 & 0.04 & $<.0001$ \\
Residual & 0.57 & 0.04 & $<.0001$ \\
Variance & 0.95 & 0.11 & $<.0001$ \\
Covariance & 2.12 & 0.30 & $<.0001$ \\
\hline
\end{tabular}

status. Specifically, the effect for parent disapproval of heavy drinking corresponds to a decrease of approximately half the odds of transitioning to heavy episodic drinking for each 1-unit increase in parental disapproval. Students who perceived greater peer disapproval of heavy drinking during the summer before college were significantly less likely to transition to weekly alcohol use, heavy episodic drinking, and consequences. A strong effect of time was observed, indicating that students were likely to transition to weekly alcohol use, heavy episodic drinking, and consequences over the first 2 years of college.

\section{Results of the intensity portion}

As depicted in Figure 1, Panel 2, the intensity portion of each of Tables 1-3 shows standardized linear regression estimates (growth and covariate prediction parameters). These estimates are interpreted as typical regression parameters; however, they apply only to the group of participants who actually reported the drinking-related outcome at some point in the study and their subsequent trend, if any. Students who intended to affiliate with the fraternity/sorority system during college reported significantly more weekly alcohol use as well as more alcohol-related consequences over time. Students who perceived higher levels of parental monitoring during the summer before college demonstrated significantly less heavy episodic drinking and fewer alcohol-related consequences over time. Students who perceived that their parents were more permissive about drinking during the students' senior year of high school reported significantly greater weekly alcohol use, heavy episodic drinking, and consequences over time. Students who perceived greater parental disapproval of heavy drinking during the summer before college reported significantly less weekly alcohol use as well as significantly fewer consequences. Students who perceived greater peer disapproval of heavy drinking during the summer before college tended to report significantly less weekly alcohol use, heavy episodic drinking, and consequences over time. A strong effect of time was also observed in the intensity portion of the model, indicating that students tended to report greater weekly alcohol use, heavy episodic drinking, and consequences over the first 2 years of college.

\section{Discussion}

The current study examined demographic, parent, and peer factors related to the natural progression of alcohol use and consequences over the transition into college. Of particular interest, several parent and peer factors predicted a differential pattern of effects for the likelihood of transitioning to use and consequences and the change in the intensity of use and consequences over the first 2 years of college. For instance, students who reported higher levels of parental monitoring were less likely to report increases in heavy 
episodic drinking over time, but parental monitoring was not related to the likelihood of transitioning to heavy episodic drinking. Also, students who reported greater parental disapproval of heavy drinking were less likely to report increases in alcohol-related consequences, but parental disapproval was not related to the onset of consequences. Alternatively, low parental permissiveness of drinking and high peer disapproval of heavy drinking appear to be particularly influential in slowing both the progression to alcohol use and consequences as well as the escalation of use and consequences. These findings extend the literature on adolescents by suggesting that parents continue to influence their children's alcohol use and consequences during the college years (Abar and Turrisi, 2008; Wood et al., 2004).

This important continuing role of parents can be regarded from two broad vantage points. First, higher levels of parental monitoring and lower levels of parental permissiveness of drinking can be seen as both promotive and protective factors in the personal ecology of college-age adolescents, as constituted by the students' ongoing relations with their parents (Jessor and Jessor, 1977; Little et al., 2007). Specifically, the degree of parental and peer influence conducive to lower levels of alcohol use can be viewed as one type of predisposing context that transmits values toward substance use (Krosnick and Judd, 1982). Our findings provide tangible evidence that this important context remains a salient one for alcohol use into the college years. Second, although we did not directly investigate the importance of risk and protective factors, our findings can also be interpreted within this framework (Hawkins et al., 1992; Jessor et al., 1995; Jessor et al., 2006). Our findings are distinct in that this is the first study to apply an emerging data analytic approach well suited for substance use outcome data to the study of parent and peer influences on collegiate alcohol use. We view our findings of reliable prospective effects for parental drinking permissiveness and monitoring as consistent with Baumrind's $(1967,1971)$ dimension of "demandingness." However, we also note that the measures used in the current study do not assess an authoritative parenting style.

There is a clear role of intended involvement with fraternity/sorority organizations and reaction to peer views in relation to alcohol use and related deleterious behaviors indicated by our study and in other recent work (Bartholow et al., 2003; Borsari and Carey, 2006; Park et al., 2008). In particular, it is striking that peer disapproval influences all three drinking outcomes both in terms of transition into the behavior and its intensity. Although not tested directly here, it is likely that the effects for intended fraternity/sorority involvement and peer disapproval reflect both selection and socialization effects (McCabe et al., 2005; Park et al., 2008). Prevention and intervention efforts that act through peer associations and networks seem promising given these results. For example, attention has been paid to incorporating peers in college student interventions, specifically brief motivational interventions (Tevyaw et al., 2007). Examining the efficacy of peer-based motivational interventions may be particularly useful in the context of fraternity and sorority involvement (Larimer et al., 2001).

The current study found that men were less likely than women to transition to weekly drinking and to begin experiencing consequences. However, cross-sectional research has consistently demonstrated that men tend to drink more alcohol than women, especially on measures of heavy drinking (O'Malley and Johnston, 2002). Our finding may reflect a ceiling effect, whereby men may transition to alcohol involvement earlier than women, resulting in fewer men transitioning during college. In addition, no differences were found between men and women on changes in alcohol involvement over the transition to college. This finding is consistent with Sher and Rutledge (2007), who reported similar increases in heavy episodic drinking among men and women. Additional research is needed to examine gender differences for the likelihood of transitioning to alcohol involvement and increases in alcohol involvement during the college years.

\section{Limitations}

Because the sample was recruited from a single public university, the results may not generalize to the U.S. college population and, particularly, to more diverse universities. However, the percentage of students who reported having consumed five or more drinks in a row in the prior 2 weeks $(33.0 \%, 47.9 \%$, and $52.1 \%$ at Waves 1,2 , and 3, respectively) is comparable to, although somewhat higher than, the findings from the Monitoring the Future study (25\% of 12th graders and $40 \%$ of college students; Johnston et al., 2007). Several other limitations to the design of our study constrain our ability to draw firm conclusions about the course of alcohol use with respect to the transition to college. Our longitudinal sample was drawn from an initial cross-sectional sample of students, not all of whom elected to continue in the study, hence, modest selection effects may have occurred. However, less than $7 \%$ of targeted participants declined to participate, and no differences were observed on the baseline measures between those who did and did not participate in the longitudinal arm of the study. In addition, we do not have a noncollege comparison sample that would enable us to compare the course of drinking behavior in same-age young people (White et al., 2006). Also, intended membership in fraternity/sorority organizations as well as peer disapproval of drinking likely reflect earlier selection into drinking status or risk status variably across individuals (Borsari and Carey, 2001; Park et al., 2008). In the case of a risk interpretation, as noted by Bartholow et al. (2003), students who are not members of fraternity/sorority organizations per se but who frequently associate with them may experience social influences similar to those of fraternity/sorority members. Our data do not reflect specific information about the connection 
between intended fraternity/sorority status and earlier drinking status to further consider these possibilities. Finally, with regard to parental influences, the influences of mothers and fathers were not analyzed separately. Notably, mothers' and fathers' permissiveness of drinking or parenting styles, for example, may differentially influence college students' alcohol use (Patock-Peckham and Morgan-Lopez, 2006, 2009). Additionally, within-person mechanisms, such as agency, control, and causal attribution, by which parenting styles may portend effects on drinking outcomes, are requisite to the overall behavioral system in which we are interested. Although not a focus of the current study, recent theory and studies point to the importance of these dimensions (Lerner and Walls, 1999; Patock-Peckham et al., 2001; Wiener, 1986).

\section{Implications}

Future research is needed to evaluate whether preventive interventions that target the parent and peer factors examined here may decrease the likelihood of alcohol involvement over the college years or decrease the intensity of alcohol use during college. Parent-based interventions that target potentially malleable factors, such as parental monitoring and disapproval of heavy drinking, may be effective at reducing college students' alcohol use and consequences. Our findings provide an enriched portrayal of the features that are salient to the course of college-age drinking; these features, when viewed as protective factors, could be incorporated into the design and refinement of preventive interventions (Hawkins et al., 1992). Preliminary evidence suggests that parentbased interventions may be effective in the college student population at reducing alcohol use and alcohol-related consequences (Ichiyama et al., 2009; Turrisi et al., 2001).

Methodologically, extending applications of mixed distribution models to the context of intervention studies provides the ability to examine conjointly the intervention's impact on students who abstain and students who are current drinkers. For alcohol researchers, this study demonstrates a recently developed approach that allows analysis given the unique characteristics of the data (i.e., clumping at zero) frequently encountered in alcohol research. Moreover, different sets of covariates can be used in the binary and intensity portions of the model, enabling development of prevention and intervention efforts aimed distinctly at initiation or intensity of drinking behavior and related outcomes. Our findings can be construed to reflect several protective factors in the students' personal social ecologies. In particular, we conclude that parents still matter in affecting the initiation and course of alcohol use and consequences in college. Future research should focus on ways in which parental influences are translated into behaviors within-person, the nature of parenting styles in emerging adulthood, and the diverse ways in which young adults may respond to parental inputs.

\section{Acknowledgments}

The authors are grateful for helpful comments from Janet Tooze on the interpretation of the parameter estimates on the intensity part of the model and for programming suggestions.

\section{References}

ABAR, C. AND TuRRISI, R. How important are parents during the college years? A longitudinal perspective of indirect influences parents yield on their college teens' alcohol use. Addict. Behav. 33: 1360-1368, 2008.

Baer, J.S., Kivlahan, D.R., Blume, A.W., McKnight, P., and Marlatt, G.A. Brief intervention for heavy-drinking college students: 4-year follow-up and natural history. Amer. J. Publ. Hlth 91: 1310-1316, 2001.

Baer, J.S., Kivlahan, D.R., and Marlatt, G.A. High-risk drinking across the transition from high school to college. Alcsm Clin. Exp. Res. 19: $54-61,1995$

Barnes, G.M., Farrell, M.P., and BanerJee, S. Family influences on alcohol abuse and other problem behaviors among black and white adolescents in a general population sample. J. Res. Adolesc. 4: 183-201, 1994.

Bartholow, B.D., Sher, K.J., and Krull, J.L. Changes in heavy drinking over the third decade of life as a function of collegiate fraternity and sorority involvement: A prospective, multilevel analysis. Hlth Psychol. 22: 616-626, 2003.

BAUMRIND, D. Child care practices anteceding three patterns of preschool behavior. Genet. Psychol. Monogr. 75: 43-88, 1967.

Baumrind, D. Current patterns of parental authority. Devel. Psychol. Monogr. 4: 1-103, 1971.

BAUMrIND, D. The influence of parenting style on adolescent competence and substance use. J. Early Adolesc. 11: 56-95, 1991.

Borsari, B. and CARey, K.B. Peer influences on college drinking: A review of the research. J. Subst. Abuse 13: 391-424, 2001.

Borsari, B. and Carey, K.B. Descriptive and injunctive norms in college drinking: A meta-analytic integration. J. Stud. Alcohol 64: 331-341, 2003.

Borsari, B. And CAREy, K.B. How the quality of peer relationships influences college alcohol use. Drug Alcohol Rev. 25: 361-370, 2006.

Boyle, J.R. and Boekeloo, B.O. Perceived parental approval of drinking and its impact on problem drinking behaviors among first-year college students. J. Amer. Coll. Hlth 54: 238-244, 2006.

BRonfenbrenner, U. The Ecology of Human Development: Experiments by Nature and Design, Cambridge, MA: Harvard Univ. Press, 1979.

Brown, E.C., Catalano, R.F., Fleming, C.B., Haggerty, K.P., and Abbott, R.D. Adolescent substance use outcomes in the Raising Healthy Children Project: A two-part latent growth curve analysis. J. Cons. Clin. Psychol. 73: 699-710, 2005.

Brown, S.A., McGue, M., Maggs, J., Schulenberg, J., Hingson, R., Swartzwelder, S., Martin, C., Chung, T., Tapert, S.F., Sher, K., Winters, K.C., Lowman, C., and Murphy, S. A developmental perspective on alcohol and youths 16 to 20 years of age. Pediatrics 121 (Suppl. No. 4): S290-S310, 2008.

BURI, J.R. Parental authority questionnaire. J. Pers. Assess. 57: 110-119, 1991.

Capone, C., Wood, M.D., Borsari, B., and Laird, R.D. Fraternity and sorority involvement, social influences, and alcohol use among college students: A prospective examination. Psychol. Addict. Behav. 21: 316327, 2007.

Dishion, T.J. And StormshaK, E.A. Intervening in Children's Lives: An Ecological, Family-Centered Approach to Mental Health Care, Washington, DC: American Psychological Assn, 2007.

Dodge, K.A., Malone, P.S., Lansford, J.E., Miller-Johnson, S., Pettit, G.S., AND BATES, J.E. Toward a dynamic developmental model of the role of parents and peers in early onset substance use. In: CLARKE-STEWART, A. And Dunn, J. (Eds.) Families Count: Effects on Child and Adolescent Development, New York: Cambridge Univ. Press, 2006, pp. 104-134. 
Duan, N., Manning, W.G., JR., Morris, C.N., and Newhouse, J.P. A comparison of alternative models for the demand for medical care. J. Bus. Econ. Stat. 1: 115-126, 1983.

Grunwald, G.K. AND Jones, R.H. Markov models for time series with mixed distribution. Environmetrics 11: 327-339, 2000.

Guilamo-Ramos, V., Jaccard, J., Turrisi, R., and Johansson, M. Parental and school correlates of binge drinking among middle school students. Amer. J. Publ. Hlth 95: 894-899, 2005.

Ham, L.S. AND Hope, D.A. College students and problematic drinking: A review of the literature. Clin. Psychol. Rev. 23: 719-759, 2003.

Hawkins, J.D., Catalano, R.F., and Miller, J.Y. Risk and protective factors for alcohol and other drug problems in adolescence and early adulthood: Implications for substance abuse prevention. Psychol. Bull. 112: 64-105, 1992.

Hingson, R., Heeren, T., Winter, M., and Wechsler, H. Magnitude of alcohol-related mortality and morbidity among U.S. college students ages 18-24: Changes from 1998 to 2001. Annual Rev. Publ. Hlth 26: 259-279, 2005.

Hurlbut, S.C. And Sher, K.J. Assessing alcohol problems in college students. J. Amer. Coll. Hlth 41: 49-58, 1992.

IChiYAma, M.A., Fairlie, A.M., WoOd, M.D., TuRrisi, R., Francis, D.P., Ray, A.E., AND STANGER, L.A. A randomized trial of a parent-based intervention with incoming college students. J. Stud. Alcohol Drugs, Supplement No. 16, pp. 67-76, 2009.

Jessor, R., Costa, F.M., Krueger, P.M., And Turbin, M.S. A developmental study of heavy episodic drinking among college students: The role of psychosocial and behavioral protective and risk factors. J. Stud. Alcohol 67: 86-94, 2006

Jessor, R. AND Jessor, S.L. Problem Behavior and Psychosocial Development, San Diego, CA: Academic Press, 1977.

Jessor, R., Van Den Bos, J., Vanderryn, J., Costa, F.M., and Turbin, M.S. Protective factors in adolescent problem behavior: Moderator effects and developmental change. Devel. Psychol. 31: 923-933, 1995.

Johnson, N.L. and Kotz, S. Discrete Distributions: Distributions in Statistics, Hoboken, NJ: John Wiley \& Sons, 1969.

Johnston, L.D., O’Malley, P.M., Bachman, J.G., and Schulenberg, J.E. Monitoring the Future: National Survey Results on Drug Use, 19752006, Vol. 2, NIH Publication No. 07-6206, Bethesda, MD: National Institute on Drug Abuse, 2007.

Krosnick, J.A. And JudD, C.M. Transitions in social influence at adolescence: Who induces cigarette smoking? Devel. Psychol. 18: 359-368, 1982.

LACHENBRUCh, P.A. Utility of logistic regression analysis in epidemiologic studies of the elderly. In: Wallace, R.B. and Woolson, R.F. (Eds.) The Epidemiologic Study of the Elderly, New York: Oxford Univ. Press, pp. 371-381, 1992

LAMBERT, D. Zero-inflated Poisson regression, with an application to defects in manufacturing. Technometrics 34: 1-14, 1992.

Land, K.C., McCAll, P.L., AND NAGIN, D.S. A comparison of Poisson, negative binomial, and semiparametric mixed Poisson regression models: With empirical applications to criminal careers data. Sociol. Meth. Res. 24: 387-442, 1996.

Larimer, M.E., Turner, A.P., Anderson, B.K., Fader, J.S., Kilmer, J.R., Palmer, R.S., AND Cronce, J.M. Evaluating a brief alcohol intervention with fraternities. J. Stud. Alcohol 62: 370-380, 2001.

LERNER, R.M. AND WALLS, T. Revisiting individuals as producers of their development: From dynamic interactionism to developmental systems. In: BrandTSTÄDTER, J. AND LeRnER, R.M. (Eds.) Action and Self-Development: Theory and Research Through the Life Span, Thousand Oaks, CA: Sage, 1999, pp. 3-36.

Little, T.D., Bovaird, J.A., AND CARD, N.A. (Eds.) Modeling Contextual Effects in Longitudinal Studies, Mahwah, NJ: Lawrence Erlbaum, 2007.

Lo, C.C. AND Globetti, G. A partial analysis of the campus influence on drinking behavior: Students who enter college as nondrinkers. J. Drug Issues 23: 715-725, 1993.

Marshall, M.P. and Chassin, L. Peer influence on adolescent alcohol use: The moderating role of parental support and discipline. Appl. Develop. Sci. 4: 80-88, 2000

McCabe, S.E., Schulenberg, J.E., Johnston, L.D., O’Malley, P.M., BachMAN, J.G., AND KLOSKA, D.D. Selection and socialization effects of fraternities and sororities on US college student substance use: A multi-cohort national longitudinal study. Addiction 100: 512-524, 2005.

Mabry, P.L., Tooze, J.A., Moser, R.P., Augustson, E.M., Malcolm, R.J., AND Benowitz, N.L. Nicotine, cotinine, withdrawal, and craving patterns during smoking and nicotine nasal spray use: Results from a pilot study with African American men. Nicotine Tob. Res. 9: 65-82, 2007.

Manning, W.G., Morris, C.N., Newhouse, J.P., OrR, L.L., Duan, N., Keeler, E.B., Liebowitz, A., Marquis, K.H., Marquis, M.S., and Phelps, C.E. A two-part model of the demand for medical care: Preliminary results from the health insurance study. In: van der GAaG, J. AND Perlman, M. (Eds.) Health, Economics, and Health Economics (Proceedings of the World Congress on Health Economics), New York: North-Holland Publishing, 1981, pp.103-123.

Masten, A.S. and Shaffer, A. How families matter in child development: Reflections from research on risk and resilience. In: Clarke-STEWART, A. And Dunn, J. (Eds.) Families Count: Effects on Child and Adolescent Development, New York: Cambridge Univ. Press, 2006, pp. 5-25.

Olsen, M.K. AND SCHAFER, J.L. A two-part random-effects model for semicontinuous longitudinal data. J. Amer. Stat. Assoc. 96: 730-745, 2001.

O'Malley, P.M. and Johnston, L.D. Epidemiology of alcohol and other drug use among American college students. J. Stud. Alcohol Supplement No. 14, pp. 23-39, 2002.

Park, A., Sher, K.J., AND KRUll, J.L. Risky drinking in college changes as fraternity/sorority affiliation changes: A person-environment perspective. Psychol. Addict. Behav. 22: 219-229, 2008.

Patock-Peckham, J.A., Cheong, J., Balhorn, M.E., and Nagoshi, C.T. A social learning perspective: A model of parenting styles, self-regulation, perceived drinking control, and alcohol use and problems. Alcsm Clin. Exp. Res. 25: 1284-1292, 2001.

Patock-Peckham, J.A. and Morgan-Lopez, A.A. College drinking behaviors: Mediational links between parenting styles, impulse control, and alcohol-related outcomes. Psychol. Addict. Behav. 20: 117-125, 2006.

Patock-Peckham, J.A. and Morgan-Lopez, A.A. The gender specific mediational pathways between parenting styles, neuroticism, pathological reasons for drinking, and alcohol-related problems in emerging adulthood. Addict. Behav. 34: 312-315, 2009.

ReAD, J.P., Wood, M.D., AND CAPONE, C. A prospective investigation of relations between social influences and alcohol involvement during the transition into college. J. Stud. Alcohol 66: 23-34, 2005.

Reifman, A. and Watson, W.K. Binge drinking during the first semester of College: Continuations and desistance from high school patterns. J. Amer. Coll. Hlth 52: 73-81, 2003.

SHER, K.J. Children of Alcoholics: A Critical Appraisal of Theory and Research, Chicago, IL: Univ. of Chicago Press, 1991.

Sher, K.J. And RutLedge, P.C. Heavy drinking across the transition to college: Predicting first-semester heavy drinking from precollege variables. Addict. Behav. 32: 819-835, 2007.

Tevyaw, T.O., Borsari, B, Colby, S.M., and Monti, P.M. Peer enhancement of a brief motivational intervention with mandated college students. Psychol. Addict. Behav. 21: 114-119, 2007.

Tooze, J.A., Grunwald, G.K., And Jones, R.H. Analysis of repeated measures data with clumping at zero. Stat. Meth. Med. Res. 11: 341-355, 2002.

Turrisi, R., Jaccard, J., TAKi, R., Dunnam, H., and Grimes, J. Examination of the short-term efficacy of a parent intervention to reduce college student drinking tendencies. Psychol. Addict. Behav. 15: 366-372, 2001.

TurRisI, R., Wiersma, K.A., AND Hughes, K.K. Binge-drinking-related con- 
sequences in college students: Role of drinking beliefs and mother-teen communications. Psychol. Addict. Behav. 14: 342-355, 2000.

van der Vorst, H., Engels, R.C.M.E., Meeus, W., Deković, M., and Van LeEuwe, J. The role of alcohol-specific socialization in adolescents' drinking behaviour. Addiction 100: 1464-1476, 2005.

Wechsler, H., Lee, J.E., Kuo, M., AND LeE, H. College binge drinking in the 1990s: A continuing problem. Results of the Harvard School of Public Health 1999 College Alcohol Study. J. Amer. Coll. Hlth 48: 199-210, 2000.

Weitzman, E.R., Nelson, T.F., And Wechsler, H. Taking up binge drinking in college: The influences of person, social group, and environment. J. Adolesc. Hlth 32: 26-35, 2003.

White, H.R., McMorris, B.J., Catalano, R.F., Fleming, C.B., Haggerty, K.P., AND ABBotT, R.D. Increases in alcohol and marijuana use during the transition out of high school into emerging adulthood: The effects of leaving home, going to college, and high school protective factors. J. Stud. Alcohol 67: 810-822, 2006.
WIENER, B. An Attributional Theory of Motivation and Emotion, New York: Springer-Verlag, 1986.

Windle, M., Spear, L.P., Fuligni, A.J., Angold, A., Brown, J.D., Pine, D., Smith, G.T., Giedd, J., And Dahl, R.E. Transitions into underage and problem drinking: Developmental processes and mechanisms between 10 and 15 years of age. Pediatrics 121 (Suppl. No. 4): S273-S289, 2008.

WitKiewitz, K. and Masyn, K.E. Drinking trajectories following an initial lapse. Psychol. Addict. Behav. 22: 157-167, 2008.

Wood, M.D., Read, J.P., Mitchell, R.E., and Brand, N.H. Do parents still matter? Parent and peer influences on alcohol involvement among recent high school graduates. Psychol. Addict. Behav. 18: 19-30, 2004.

Wood, M.D., Read, J.P., Palfai, T.P., and Stevenson, J.F. Social influences and alcohol use and misuse among college students: The mediational role of alcohol outcome expectancies. J. Stud. Alcohol 62: 32-43, 2001. 